\title{
Differential expression of endothelin-2 along the mouse intestinal tract
}

\author{
Satoshi Takizawa1, Tsuyoshi Uchide ${ }^{2}$, Javier Adur ${ }^{1,3}$, Takaharu Kozakai ${ }^{1}$, \\ Eiichi Kotake-Nara ${ }^{1,3}$, Jiexia Quan ${ }^{1}$ and Kaname Saida ${ }^{1,4}$ \\ ${ }^{1}$ Institute for Biological Resources and Functions, National Institute of Advanced Industrial Science and Technology (AIST), Tsukuba, Ibaraki 305-8566, Japan \\ ${ }^{2}$ Department of Toxicology, School of Veterinary Medicine and Animal Sciences, Kitasato University, Towada, Aomori 034-8628, Japan \\ ${ }^{3}$ New Energy and Industrial Technology Development Organization (NEDO), 16F, MUZA KAWASAKI Central Tower 1310 Omiya-cho, Saiwai-ku, Kawasaki, Kanagawa \\ 212-8554, Japan \\ ${ }^{4}$ Human Stress Signal Research Center, National Institute of Advanced Industrial Science and Technology (AIST), Ikeda, Osaka 536-8577, Japan
}

(Requests for offprints should be addressed to K Saida; email: k.saida@ aist.go.jp)

\begin{abstract}
Endothelin (ET)-2, an ET family peptide, is highly expressed in intestine. However, the specific distribution and function of ET-2 remain unknown. We elucidated the expression profile and localization of ET-2 in mouse gastrointestinal tract. Real-time PCR analysis revealed that ET-2 gene expression in the gastrointestinal tract of healthy animals was relatively high in the colon. Immunohistochemical analysis revealed ET-2-like immunoreactivity mainly in epithelial cells of the mucosa throughout the intestinal tract of healthy animals. Intracellularly, ET-2 was concentrated close to the basement membrane of intestinal epithelial cells. A weak ET-2-like immunoreactivity was also localized to some neurofibers and the myenteric plexus of the muscle layer, coexpressing with vasoactive intestinal peptide. ET-2-like immunoreactivity was also detected at Brunner's glands of the duodenum and follicle-associated epithelium of Peyer's patch. In contrast, ET-1-like immunoreactivity was uniformly distributed in epithelial cells. In dextran sulfate sodium (DSS)-induced colitis, colonic ET-2 was upregulated during the late stage of DSS treatment. These results suggest that in intestinal epithelial cells ET-2 could be secreted into the lamina propria and the dome region in Peyer's patch, and that it might modulate immune cells in these sites for mucosal defense.
\end{abstract}

Journal of Molecular Endocrinology (2005) 35, 201-209

\section{Introduction}

The endothelin (ET) system comprises three ligands, ET-1, ET-2 and ET-3, as well as two G-protein-coupled receptors, the ET A receptor (ETA) and the ET B receptor (ETB). The ligands (ETs), 21-amino acid peptides, have potent vasoconstrictive activity and control many cellular processes including gene expression, differentiation, apoptosis and cell growth (Kedzierski \& Yanagisawa 2001). ETs produce their biological effects via activation of the two receptor subtypes. Whereas ETA binds ET-1 and ET-2 under physiological conditions, ETB binds all three ETs with equal affinity.

Mammalian ET-2 has a mouse and rat ortholog known as vasoactive intestinal contractor (VIC). VIC differs from human ET-2 by one amino acid out of 21 amino acid residues: Asn-4 is replaced with Ser-4 in human ET-2 (Inoue et al. 1989, Saida et al. 1989, 2000, Bloch et al. 1991). In this article, we use the term murine ET-2 in place of VIC. Structurally, ET-2 isoforms are highly homologous to ET-1 (Inoue et al. 1989, Saida et al. 1989). Previous studies showed that the ET-2 gene is strongly expressed in and largely limited to the gastrointestinal tract, sex organs and pituitary gland (Saida et al. 1989, Fang et al. 1994, Uchide et al. 2000a,b, Masuo et al. 2003), whereas ET-1 is expressed in many tissue types. As the receptor selectivity of ET-2 is similar to that of ET-1, many of the biological activities of ET-2 overlap with those of ET-1. However, several recent reports demonstrate ET-2-specific functions distinct from those of ET-1. First, hypoxia upregulates ET-2 mRNA in breast tumor cell lines, and ET-2 acts as a hypoxia-induced autocrine survival factor for breast tumor cells (Grimshaw et al. 2002a). Second, ET-2 is a chemoattractant for macrophages and may modulate macrophage distribution in tumors (Grimshaw et al. 2002b). Third, ET-2 may be involved in the invasion of tumor cells (Grimshaw et al. 2004). Finally, ET-2 is one of four candidate tumor markers in uveal melanoma cell lines and may be involved in uveal melanoma development (Zuidervaart et al. 2003).

Several studies concerning the ET system in the intestine have been reported. ET-1 mRNA was detected in the epithelium, macrophages and stromal cells of the lamina propria in human large intestine (Egidy et al. 2000, Massai et al. 2003). ET-1 and ET-3 peptides 
are localized to the mucosa in rat intestine (Takahashi et al. 1990). ET-1-like immunoreactivity also was observed in the neurons of human colon, and it has been suggested that ET-1 modulates intestinal motility and secretion, acting as a neuropeptide (Inagaki et al. 1991, Escrig et al. 1992). Studies with mice deficient in ET-3 have demonstrated that ET-3 is essential for the development of enteric neurons (Baynash et al. 1994). Although it is reported that ET-2 mRNA is predominantly expressed in stromal cells of the lamina propria (de la Monte et al. 1995), no detailed information on the expression and distribution of ET-2 peptide is available.

Inflammatory bowel disease (IBD) is a chronic inflammatory disorder of the intestine that is considered to arise from dysregulation of mucosal immunity. In human IBD, the tissue ET-1 level was found to be elevated (Murch et al. 1992). A recent report showed that ET-2 gene expression was more predominant than ET-1 in human colon, although the ET-2 mRNA level was not significantly changed in human IBD (McCartney et al. 2002). In an animal model of IBD, 2,4,6trinitrobenzene sulfonic acid (TNBS)-induced colitis in rat, the gene expression of ET-1 was predominant over ET-2 gene expression (McCartney et al. 2002). An ET antagonism study showed that the ET system is involved in tissue injury due to TNBS-induced colitis (Hogaboam et al. 1996). Although it has been shown that ET-1 is involved in the pathogenesis of IBD, little is known regarding the pathological role of ET-2.

In this study, in an attempt to elucidate the specific physiological and pathophysiological roles of ET-2 in vivo, we determined the localization of ET-2 in mouse intestinal tract and compared it with that of ET-1. In addition, we elucidated the differences in colonic ET-2-like immunoreactivity between normal mice and mice with dextran sulphate sodium (DSS)-induced colitis. The implication of these observations is discussed.

\section{Materials and methods}

\section{Animals}

Male ICR mice (7-12 weeks old) were purchased from Japan Clea (Tokyo, Japan) and were housed under conventional conditions. This study was approved by the Animal Care Committee at the National Institute of Advanced Industrial Science and Technology, Japan.

\section{Quantitative real-time PCR}

Total RNA was isolated from six segments of the mouse gastrointestinal tract (stomach, duodenum, jejunum, ileum, colon and rectum) with Isogen (Nippon Gene, Tokyo, Japan). cDNA was synthesized using an RNA PGR kit (AMV ver.2·1; TaKaRa Bio, Shiga, Japan). Real-time PCR was performed as previously described
(Uchide et al. 2000b). Real-time PCR for ET-1, ET-2 and glyceraldehyde-3-phosphate dehydrogenase (GAPDH) was performed using the TaqMan PCR Core Reagent Kit (Applied Biosystems, Foster City, CA, USA). Composition of the forward and reverse primers and the TaqMan probe for ET-1, ET-2 and GAPDH are as follows: ET-1 forward primer, 5"TTC CGG TGA TCT TCT CTC TGC T3'; ET-1 reverse primer, 5'TCT GCT TGG CAG AAA TTC CA3'; ET-1 probe, 5'-FAM-ACA AGG AGT GTG TGT ACT TGT GCG ACG TGG-TAMRA-3'; ET-2 forward primer, 5'CTG CGT TTT CGT CGT TGG T3'; ET-2 reverse primer, 5'TGG AGG TGA TGG TGT TAT CTC TTC3'; ET-2 probe, 5'-FAM-CTG CAA CTC CTG GCT TGA CAA GGA A-TAMRA-3'; GAPDH forward primer, 5'CTT CAG CAC CAT GGA GAA GGC3'; GAPDH reverse primer, 5'GGG ATG GAC TGT GGT GAT GAG3'; GAPDH probe, 5'-FAM-CGT GGG CAA GGT CAT CGA TGA CAA CTT T-TAMRA-3'. Real-time PCR was monitored on an ABI PRISM 7700 Sequence Detection System (Applied Biosystems). Reaction conditions were $95^{\circ} \mathrm{C}$ for $10 \mathrm{~min}$ followed by 50 cycles of the amplification step $\left(95^{\circ} \mathrm{C}\right.$ for $20 \mathrm{~s}$ and $60{ }^{\circ} \mathrm{C}$ for $\left.2 \mathrm{~min}\right)$. Gene-expression levels of ET-1, ET-2 and GAPDH were calculated using standard curves. ET-expression levels were normalized to GAPDH and presented as gene-expression rates:

ET expression $=($ amount of ET-1 or ET-2 mRNA)/ (amount of GAPDH mRNA) × 100 .

\section{Induction of colitis}

Male 7-week-old ICR mice were used in this study. Experimental colitis was induced by oral administration of 5\% (w/v) DSS (molecular mass, $40000 \mathrm{Da}$; ICN Biomedicals, Aurora, OH, USA) in distilled water ad libitum for 7 days.

\section{Immunohistochemistry}

Gastrointestinal segments were fixed with $2 \%$ paraformaldehyde $/ 15 \%$ saturated picric acid in $0.15 \mathrm{M}$ sodium phosphate buffer $\left(\mathrm{pH} 7 \cdot 3,4{ }^{\circ} \mathrm{C}, 2 \mathrm{~h}\right)$ and embedded in Optimal cutting temperature (OCT) compound (Tissue-Tek, Torrance, CA, USA). The immunohistochemistry was performed as follows. For ET-2 detection, the $8 \mu \mathrm{m}$-thick sections were blocked with 5\% heat-inactivated normal goat serum/0 $1 \%$ sodium azide/PBS; the primary antibody was rabbit anti-ET-2 antibody (Yanaihara Institute, Shizuoka, Japan; diluted $\left.1: 64 ; 37^{\circ} \mathrm{C}, 2 \mathrm{~h}\right)$ and the secondary antibody was biotin-labeled goat anti-rabbit IgG (Vector Laboratories, Burlingame, CA, USA; diluted 1:250; $\left.37^{\circ} \mathrm{C}, 30 \mathrm{~min}\right)$. The sections were treated with $0 \cdot 3 \%$ hydrogen peroxide in methanol (room temperature, $30 \mathrm{~min}$ ) after the primary antibody reaction. Subsequent 
immunostaining procedures were performed using the peroxidase Vectastain Elite ABC Kit (Vector Laboratories) and the DAB Substrate Kit (Vector Laboratories) as a substrate, according to the manufacturer's recommendations. For ET-1 detection, the sections were blocked by the same procedure used for ET-2; the primary antibody was rabbit anti-ET-1 antibody (code 18201; Immuno-Biological Laboratories, Gunma, Japan; cross reactivity, ET-1, 100\%; ET-2, 1\%; ET-3, $0 \cdot 4 \%$; big ET-1, $100 \%$; big ET-2, $0 \cdot 2 \%$; big ET-3, $0.4 \%$; VIC, $0.2 \%, 1: 10$; room temperature, $1 \mathrm{~h}$ ) and the secondary antibody was the same as that used for detection of ET-2 (room temperature, $30 \mathrm{~min}$ ). The sections were treated with $0.3 \%$ hydrogen peroxide in methanol (room temperature, $30 \mathrm{~min}$ ) before the blocking reaction. The avidin-biotin complex method was performed with the peroxidase Vectastain ABC Kit, and the substrate was the same as that used for ET-2 detection. Sections were counterstained with Alcian Blue. To demonstrate that the immunohistochemical reaction was specific, the diluted antibody was absorbed onto VIC or ET-1 peptide-immobilized Affi-Gel 10 agarose beads (Bio-Rad, Hercules, CA, USA) prior to immunostaining.

\section{Immunodoublefluorescence}

Sections were incubated with rabbit anti-ET-2 antibody (1:64) and guinea pig anti-vasoactive intestinal peptide (VIP) serum (Euro-Diagnostica, Medeon, Sweden; diluted $1: 1000 ; 4{ }^{\circ} \mathrm{C}$, overnight). After washing with PBS, fluorescein isothiocyanate (FITG)-labeled donkey anti-rabbit IgG (Chemicon, Temecula, CA, USA; diluted 1:200) and rhodamine isothiocyanate (RITC)labeled donkey anti-guinea pig IgG (Chemicon; diluted 1:200) were applied $\left(37^{\circ} \mathrm{C}, 30 \mathrm{~min}\right)$. After staining, sections were mounted with Vectashield Mounting Medium (Vector Laboratories). Confocal microscopy was performed on a Zeiss LSM410 microscope (Carl Zeiss, Oberkochen, Germany).

\section{Lectin staining}

For detection of M-cells in Peyer's patch, we performed lectin staining of Peyer's patch by the method of Giannasca et al. (1994) with minor modification. Cryosections were blocked with $1 \%$ BSA/PBS (room temperature, $2 \mathrm{~h}$ ) and incubated with $50 \mu \mathrm{g} / \mathrm{ml}$ RITClabeled Ulex europaeus agglutinin type I (UEA-I; EY Laboratories, San Meteo, CA, USA; room temperature, $30 \mathrm{~min}$ ). The specificity of lectin binding was assessed by preincubation of RITC-labeled UEA-I with its cognate monosaccharide, $\alpha$-L-fucose at a concentration of $0 \cdot 2 \mathrm{M}$ for $2 \mathrm{~h}$ before reaction with sections. After washing with PBS, immunofluorescence for ET-2 was performed by the method described above.

\section{In situ hybridization}

In situ hybridization using digoxigenin-labeled riboprobes was performed with an ISHR Starting Kit (Nippon Gene). The cloned ET-2 cDNA plasmid (pCR-Script SK+; Stratagene, La Jolla, CA, USA) was used as a template for synthesizing the riboprobes. Digoxygenin-labeled riboprobes were synthesized using the DIG RNA Labeling Kit (Boehringer Mannheim, Mannheim, Germany). Excised intestinal (duodenal) tissue was fixed with $4 \%$ paraformaldehyde/PBS $\left(4{ }^{\circ} \mathrm{C}\right.$, overnight) and embedded in OGT compound. The $10 \mu$-thick cryosections were treated with $0 \cdot 2 \mathrm{M} \mathrm{HCl}$ (room temperature, $20 \mathrm{~min}$ ), $5 \mu \mathrm{g} / \mathrm{ml}$ proteinase $\mathrm{K}$ (Boehringer Mannheim) in PBS $\left(37^{\circ} \mathrm{C}, 10 \mathrm{~min}\right)$ and $2 \mathrm{mg} / \mathrm{ml}$ glycine in PBS (room temperature, $15 \mathrm{~min}$ ), and acetylated with $0 \cdot 25 \%$ acetic anhydride in $0 \cdot 1 \mathrm{M}$ triethanolamine hydrochloride $(\mathrm{pH} 8 \cdot 0$; room temperature, $15 \mathrm{~min})$. After prehybridization with $2 \times \mathrm{SSC}$ containing $50 \%$ formamide $\left(50{ }^{\circ} \mathrm{C}, 30 \mathrm{~min}\right)$, the sections were hybridized with hybridization buffer $(50 \%$ formamide, $2 \times \mathrm{SSC}, 1 \mu \mathrm{g} / \mu \mathrm{l} \mathrm{RNA}, 1 \mu \mathrm{g} / \mu \mathrm{l}$ sonicated salmon sperm DNA, $1 \mu \mathrm{g} / \mu \mathrm{l}$ BSA and $10 \%$ dextran sulfate) containing $1 \mu \mathrm{g} / \mu \mathrm{l}$ digoxygenin-labeled riboprobe $\left(50{ }^{\circ} \mathrm{C}\right.$, overnight). The sections were incubated with alkaline phosphatase-labeled anti-digoxygenin antibody (Boehringer Mannheim; 1:500), and visualized with Nitro Blue Tetrazolium and 5-bromo-4-chloro-3indolylphosphate. Sections were counterstained with Methyl Green.

\section{Statistical analysis}

The results are shown as means \pm S.D. and analyzed by Scheffe's $F$ test to identify significant differences among the data. $P$ values lower than 0.05 were considered significant.

\section{Results}

\section{Gene-expression profiles of ET-2 and ET-1 in normal mouse gastrointestinal tract}

To assess the expression of the ET-2 gene, we performed real-time PCR analysis of ET-2 in normal mouse gastrointestinal tract, and compared the results with those for ET-1 (Fig. 1). While the gene expression of ET-1 was higher than that of ET-2 in the stomach, ET-2 gene expression exceeded that of ET-1 in the ileum $(P<0 \cdot 05)$. Among the tissues of the gastrointestinal tract, the level of ET-2 was significantly higher in the colon than in the stomach $(P<0 \cdot 05)$.

\section{Localization of ET-2 in normal mouse intestinal tract}

To determine the localization of ET-2, we examined the immunohistochemistry of ET-2 in normal mouse 


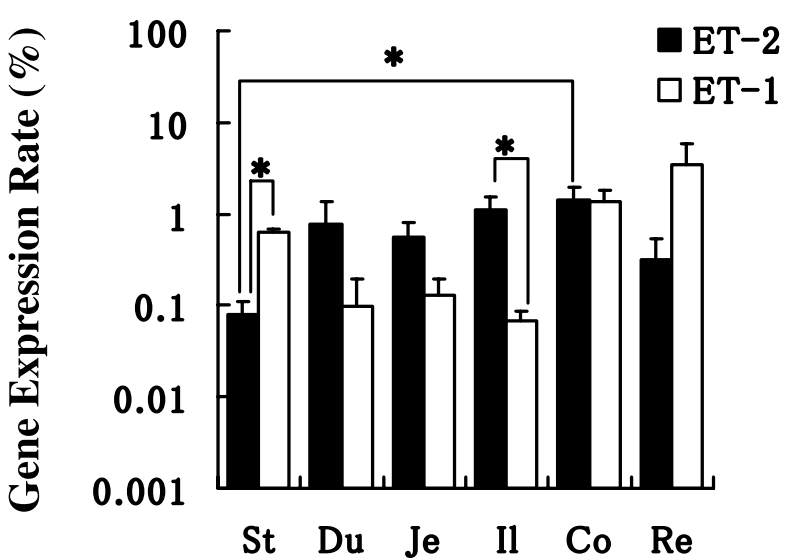

Mouse Gastrointestinal Tract

Figure 1 Gene-expression profiles of ET-2 and ET-1 in normal mouse gastrointestinal tract. The gene-expression levels of ET-2 ( $\square$ ) and ET-1 ( $\square$ ) were quantified by real-time PCR. St, stomach; Du, duodenum; Je, jejunum; II, ileum; Co, colon; Re, rectum. The results are shown as means \pm S.D $(n=4)$.

Statistically significant differences between groups are shown; ${ }^{*} P<0.05$.

intestinal tract: colon (Fig. 2A and C), ileum (Fig. 3A, B and $\mathrm{C}$ ), Peyer's patch (Fig. 3D and E) and duodenum (Fig. $3 \mathrm{~F}$ and $\mathrm{G}$ ). Within the intestinal tract, most of the ET-2-like immunoreactivity was localized to the mucosal layer, observed mainly in epithelial cells (Figs 2A, 3A and $3 \mathrm{~F})$. Most epithelial cells showed intracellular ET-2 to be concentrated in the vicinity of the basement membrane throughout the intestinal tract: colon, ileum, Peyer's patch and duodenum (Figs 2A, 3A, 3D and 3F). However, ET-2-like immunoreactivity was very weak at the lamina propria (Fig. 3A and F). Compared with the mucosal layer, ET-2-like immunoreactivities of the submucosa and muscle layers were weak (Figs 2C, 3B and 3 F). In contrast, colonic ET-1-like immunoreactivity was uniformly distributed in the epithelial cells, and surface epithelial cells showed a higher concentration of ET-1 (Fig. 2B). In addition, ET-1-like immunoreactivity was also observed in scattered neurofibers and myenteric plexus of the muscle layer (Fig. 2D). At other intestinal sites (ileum, Peyer's patch and duodenum), ET-1 showed a similar localization pattern as in the colon (data not shown).

Immunohistochemical analysis of the colon revealed that the highest ET-2-like immunoreactivity was located at the tips of surface epithelia (Fig. 2A), as was observed for ET-1 (Fig. 2B). Along the bottom-up axis of colonic crypt, a gradient-like expression of ET-2 was observed (Fig. 2A). Whereas the top of colonic crypt showed higher expression of ET-2, the bottom of colonic crypt showed lower expression of ET-2 (Fig. 2A). In the ileum, it was more obvious than in the colon (Fig. 2A) that the highest concentration of ET-2 occurred in the vicinity of the basement membrane in epithelial cells (Fig. 3A). Along the villus-crypt axis in the ileum, a gradient-like expression of ET-2 was observed (Fig. 3A). However, the gradient-like pattern of ileal ET-2 was different from that of colon. Whereas ileal ET-2 was expressed more strongly at the bottom of the villus-crypt axis than at the top, colonic ET-2 was expressed higher at the top of the crypt than at the bottom (Figs 2A and 3A). Immunohistochemical studies along the transverse section also supported this finding (Fig. 3C). In Peyer's patch, ET-2 immunostaining showed that whole cells of the follicle-associated epithelium (FAE) were stained at the highest level, whereas the lymphoid follicle was not stained (Fig. 3D). FAE consists of two kinds of cells, absorptive enterocytes and M-cells. M-cells are the center of mucosal immunity and are specifically stained by the $\alpha$-L-fucose-binding lectin UEA-I (Giannasca et al. 1994). To confirm distribution of ET-2 in M-cells, we stained M-cells with RITC-labeled UEA-I and analyzed the immunofluorescence of ET-2. Immunofluorescence analysis revealed the presence of ET-2 in M-cells (Fig. 3E). In FAE, ET-2 was localized to the vicinity of the basement membrane, as observed in other intestinal tissues. In the duodenum, villous epithelial cells showed the highest ET-2-like immunoreactivity, and Brunner's glands showed the second highest (Fig. $3 \mathrm{~F}$ and $\mathrm{G}$ ).

\section{Colocalization of ET-2 with neuronal marker VIP in myenteric plexus and muscular neurofibers}

To confirm ET-2-like immunoreactivity in the intestinal muscle layer, we performed immunodoublefluorescence of ET-2 and VIP in the colonic muscle layer. VIP is a neuropeptide that expresses in enteric neurons including scattered neurofibers and the myenteric plexus (Sundler et al. 1988). We used this peptide as a neuronal marker and compared its localization with that of ET-2. ET-2-like immunoreactivity was found in some scattered neurofibers and the myenteric plexus of the colonic muscle layer (Fig. 2E), although immunoenzymatic detection of ET-2 showed very weak immunoreactivity in the intestinal muscle layer (Figs 2C and 3B). In some ET-2-positive scattered neurofibers and the myenteric plexus, VIP was colocalized (Fig. 2 G).

\section{Localization of ET-2 mRNA in mouse duodenum}

To determine the cellular distribution of ET-2 mRNA, we performed in situ hybridization for ET-2 in mouse duodenum. ET-2 mRNA was located predominantly in epithelial cells (Fig. 3H). ET-2 mRNA was also observed at the myenteric plexus (Fig. 3H). However, ET-2 mRNA was not detected in stromal cells of the lamina propria (Fig. 3H). No signal was detected in the sections by a sense probe (data not shown). Together with the 


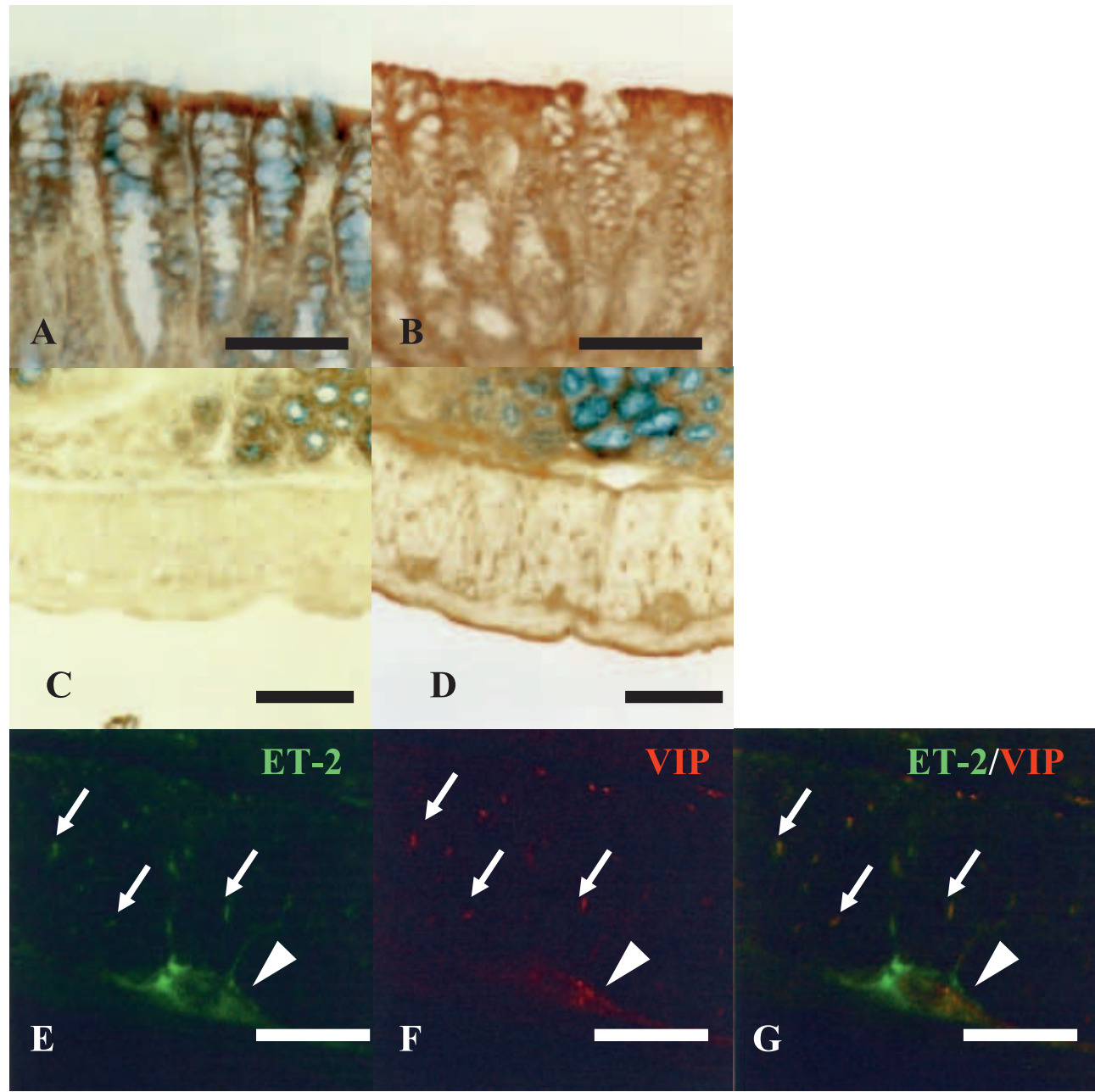

Figure 2 Immunohistochemistry of ET-2 and ET-1 in normal mouse colon. (A-D) Immunohistochemistry of ET-2 and ET-1. The longitudinal sections of colonic mucosa $(A, B)$ and colonic muscle $(C, D)$ were immunostained with an anti-ET-2 antibody $(A, C)$ or an anti-ET-1 antibody $(B, D)$. Blue color shows staining with Alcian Blue. Scale bars, $100 \mu \mathrm{m}(A, B)$ and $50 \mu \mathrm{m}(C, D)$. (E-G) Immunodoublefluorescence of ET-2 and VIP. The longitudinal sections of colonic muscle (E-G) were double-stained with an anti-ET-2 antibody (E, G; green) and an anti-VIP antiserum (F, G; red). The merged images of each co-staining are depicted in panel $\mathrm{G}$ (yellow). Some scattered neurons (arrows) and myenteric plexus (arrowheads) were stained with ET-2 and VIP. Scale bars, $100 \mu \mathrm{m}$.

immunohistochemical studies (Fig. 3F), we conclude that duodenal epithelial cells highly express ET-2 mRNA and peptide.

\section{Upregulation of ET-2 during the late stage of DSS treatment}

To assess whether the localization pattern of intestinal ET-2 changes under pathological conditions, we analyzed the localization pattern of colonic ET-2 during DSS-induced colitis. Downregulation of ET-2 peptide was noted at the early stage (day 1 ) of DSS-induced colitis (Fig. 4C), compared with a normal control (day 0,
Fig. 4A). The ET-2 peptide level increased in colonic epithelial cells during the late stage (days 3-7) of DSS treatment (Fig. 4E, G and I), compared with a normal control (day 0, Fig. 4A). From day 1 to day 5 inflammation was not detected clearly (Fig. 4D, F and $\mathrm{H})$. At day 7, evidence of inflammation - infiltration of inflammatory cells and focal disappearance of mucosal crypts - was observed (Fig. 4J).

\section{Discussion}

We have determined for the first time the cellular distribution of ET-2 mature peptide in mouse intestinal 


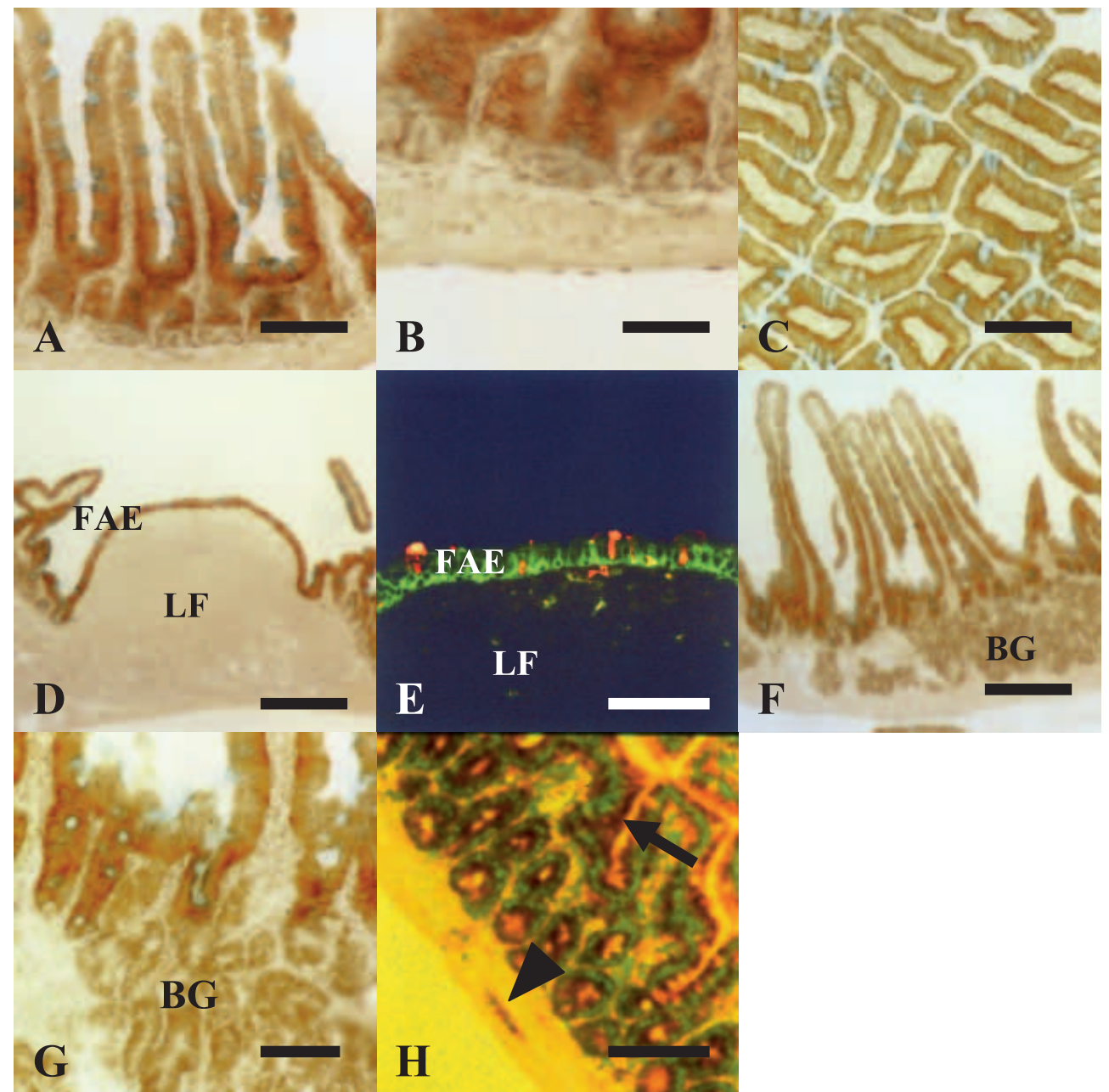

Figure 3 Localization of ET-2 mRNA and peptide in normal mouse small intestine. (A-C)

Immunohistochemistry of ET-2 in normal mouse ileum. The longitudinal section of ileal mucosa (A), ileal muscle (B) and transverse sections of the villus in ileum (C) were immunostained by an anti-ET-2 antibody. Blue color shows staining with Alcian Blue. Scale bars, $50 \mu \mathrm{m}(A)$ and $25 \mu \mathrm{m}(\mathrm{B}, \mathrm{C})$. (D, E) Localization of ET-2 in Peyer's patch. (D) Immunohistochemistry of ET-2. Blue color shows staining with Alcian Blue. FAE, Follicle Associated Epithelium; LF, lymphoid follicle. (E) Double-staining of ET-2 and UEA-I-binding sugar (M-cell marker). Peyer's patch was double-stained with anti-ET-2 antibody (green) and RITC-labeled UEA-I (red). Scale bars, $100 \mu \mathrm{m}(\mathrm{D})$ and $25 \mu \mathrm{m}(\mathrm{E})$. (F-H) Distribution of ET-2 mRNA and peptide in duodenum. (F, G) Immunohistochemistry of ET-2. Blue color shows staining with Alcian Blue. BG, Brunnel's gland. $(\mathrm{H})$ In situ hybridization of ET-2. In the section hybridized with an antisense probe, ET-2 mRNA signals (dark brown, arrow) were found predominantly around the nuclei (green) of epithelial cells. ET-2 mRNA was also localized in the myenteric plexus (arrowhead). Scale bars, $100 \mu \mathrm{m}(\mathrm{F})$ and $50 \mu \mathrm{m}(\mathrm{G}, \mathrm{H})$.

tract. ET-2 peptide is predominantly localized to the epithelial cells of the mucosal layer in the intestinal tract (Figs 2 and 3). This finding corresponds to the localization of ET-2 mRNA (Fig. 3H). In particular, intestinal ET-2 is concentrated in the vicinity of the basement membrane in epithelial cells. On the contrary, ET-1 is distributed widely in many cells of both the mucosal and muscle layers at all intestinal sites. The distribution of ET receptors in intestine was analyzed by ${ }^{125}$ I-ET-1 ligand-binding assay (Koseki et al. 1989, Inagaki et al. 1991, Okabe et al. 1995). These reports revealed that ET-1-binding sites are localized mainly in the mucosal layer and the myenteric plexus. These findings suggest that both ET receptors, ETA and ETB, are localized in these regions of the intestine. We also analyzed the distribution of ETA and ETB in intestine by immunohistochemistry. Whereas ETA is widely and uniformly distributed in both the mucosal and muscle 


\section{ET-2 HE}

\section{Day 0 (control)}

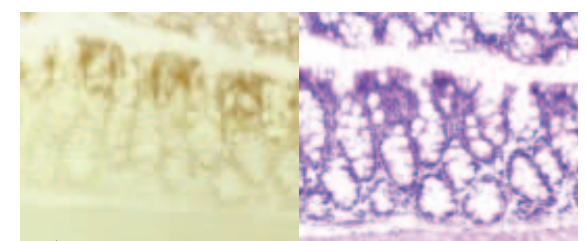

A

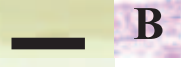

B. 20

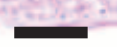

Day 1

Day 3

\section{Day 5}

Day 7
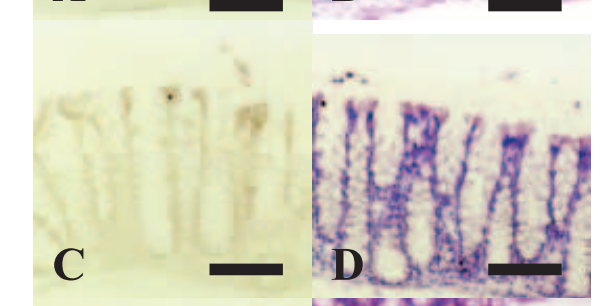

C
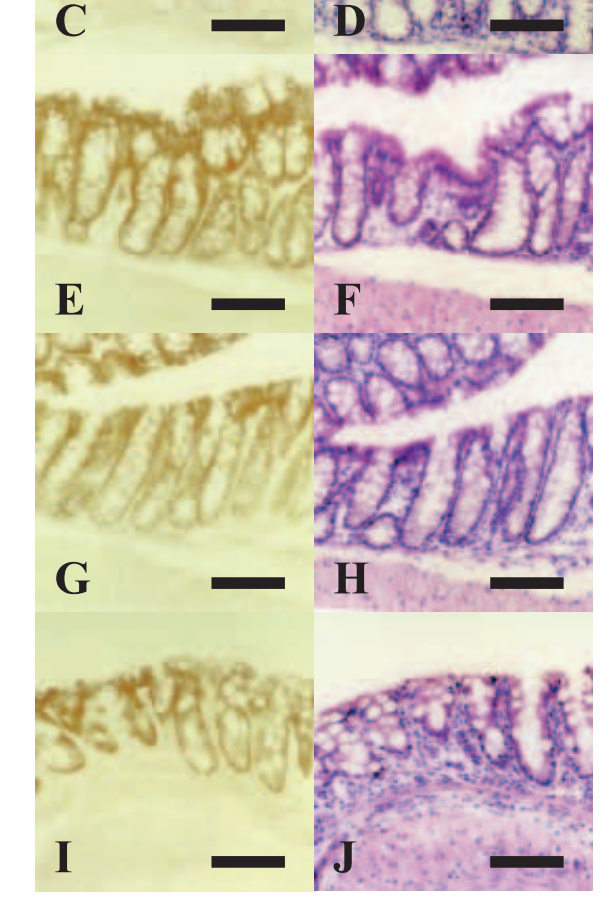

Figure 4 Immunohistochemistry of ET-2 in normal and DSS-treated colon. Sections were treated with anti-ET-2 antibody (A, C, E, G, I). Consecutive sections were stained by hematoxylin and eosin (HE; B, D, F, H, J). (A, B) Normal mouse colon (day 0; without DSS treatment). (C-J) DSS-treated mouse colon at day $1(C, D)$, day $3(E, F)$, day 5 $(\mathrm{G}, \mathrm{H})$ and day $7(\mathrm{I}, \mathrm{J})$. In all cases ET-2 was detected exclusively in epithelial cells. The expression of ET-2 increased in epithelial cells during late stages of DSS treatment.

Representative images are shown $(n=5)$. Scale bars, $50 \mu \mathrm{m}$.

layers (Satoshi Takizawa, Javier Adur \& Kaname Saida, unpublished observations), ETB is expressed in the nuclei of epithelial cells, stromal cells in the lamina propria and neurons in the muscle layer (Takizawa et al. 2004). A recent report showed that ETB is localized in nuclei and may function as an 'intracrine' receptor for intracellular ET ligands (Boivin et al. 2003). These results demonstrate that the cellular distribution of ET-2 corresponds to the distribution of its receptors in the intestinal tract. Thus it is suggested that ET-2 functions in an intracrine/autocrine/paracrine fashion in the intestinal tract and may modulate intestinal function.

Previous reports (de la Monte et al. 1995, Liu et al. 1998) presented localization patterns for rat ET-2 mRNA and precursor peptide (big ET-2) in the gastrointestinal tract that differed from the patterns we observed for mouse (this study). These earlier studies revealed that rat ET-2 mRNA and big ET-2 were expressed mainly in stromal cells of lamina propria. On the contrary, we found that mouse ET-2 mRNA and mature peptide were expressed predominantly in epithelial cells of intestinal tract, and displayed very weak signals in stromal cells of lamina propria. For both mouse and rat, the correspondence between the distribution of mRNA and peptide is consistent. Moreover, de la Monte et al. (1995) determined the gene-expression profiles of rat ET-2 and ET-1 in gastrointestinal tract by RNase-protection assay (de la Monte et al. 1995). We analyzed the same expression profiles using real-time PCR (Uchide et al. 2000a), and our rat data are largely consistent with those of de la Monte et al. Earlier we had determined the gene-expression pattern of mouse ET-2 in various tissues by semi-quantitative reverse transcriptase PCR and showed that the gene expression of mouse ET-2 in the intestine was higher than in the stomach (Uchide et al. 1999). These data also support our current data. However, the gene-expression profiles of mouse ET-2 and ET-1 in gastrointestinal tract are somewhat different from those of rat (Fig. 1). We speculate that the differences in expression profiles between rat and mouse may arise from species differences or depend on unidentified physiological conditions. Further analysis is needed to determine the reasons for these differences.

The localization of epithelial ET-2 leads us to a hypothesis for ET-2-specific functions in the intestine. First, basal localization of ET-2 indicates that ET-2 may be secreted from the basement membrane of epithelial cells into the lamina propria where it could modulate the mucosal immune system. Takahashi-Iwanaga et al. (1999) reported that the basement membrane of epithelial cells has many small pores running along the entire length of the villus in mouse intestine, and that the epithelial cells interact with macrophages in the lamina propria through these pores. In addition, a recent report demonstrated that ET-2 is a chemoattractant for macrophages (Grimshaw et al. 2002b). Moreover, ETs have immunomodulating activity and control Th1/Th2 cytokine balance in mast cells (Coulombe et al. 2002). These findings suggest that ET-2 could be secreted from colonic epithelial cells and FAE in Peyer's patch into the lamina propria and lymphoid follicle, respectively, where it might modulate the immune system for mucosal 
defense. As M-cells in Peyer's patch are the center of mucosal immunity, ET-2 in M-cells might play a crucial role in antigen presentation. Second, ET-2 might be involved in the apoptosis of colonic surface epithelial cells. Interestingly, ET-2 and ET-1 are expressed most highly in these cells, and it is well known that these cells are apoptotic. In addition, Lauber et al. (2003) showed that apoptotic cells secrete the chemoattractant factor lysophosphatidylcholine, which stimulates the attraction of phagocytes. This study suggests that apoptotic cells present attraction signal to ensure their efficient removal after cell death. It is possible that ET-2 could be secreted from apoptotic cells and might function as chemoattraction signal for phagocytes. Third, ET-2 might be involved in the differentiation of epithelial cells. It is well known that intestinal epithelial cells migrate toward the intestinal lumen, and the differentiation of epithelial cells in the small intestine and the colon depend on the position along the villus-crypt axis of the small intestine and the bottom-up axis of the colonic crypt, respectively. In addition, we observed that the intestinal ET-2-like immunoreactivity exhibits a gradient-like pattern along the villus-crypt axis of the small intestine and also along the bottom-up axis of colonic crypt (Figs 2A and 3A). These observations suggest that ET-2 might control the differentiation of intestinal epithelial cells through its gradient-like expression.

In the muscle layer, ET-2 is localized to some VIPpositive scattered neurons and the myenteric plexus. Previous reports showed that ET-2 has contractile activity in the ileum (Ishida et al. 1989) and in cultured human aortic smooth muscle cells (Iwashima et al. 1997). Thus, it is suggested that ET-2 in the muscle layer acts as a neuropeptide and controls smooth muscle contraction.

We further speculate on other ET-2 functions in the intestinal tract. In the duodenum, ET-2 is observed at the highest level in epithelial cells, and at the second highest in Brunner's gland (Fig. 3F and G). Brunner's glands secrete alkaline mucus to neutralize acidic gastric juice. Thus, it is suggested that ET-2 plays a role in the neutralization function of Brunner's glands.

The expression of ET-2 during DSS-induced colitis was also determined. DSS-induced colitis is an experimental animal model of human IBD and resembles ulcerative colitis (Okayasu et al. 1990). Colonic ET-2 was upregulated during the late stage of DSS treatment, although the localization pattern of ET-2 was basically the same in the DSS-treated mouse colon as in normal colon (Fig. 4). As described above, it is suggested that upregulated ET-2 is secreted from the basement membrane into the lamina propria during DSS-induced colitis, and that it attracts macrophages to the lamina propria for mucosal defense. This study also showed that ET-2 was expressed in morphologically preserved epithelial cells during DSS-induced colitis, and we can use ET-2 as an epithelial marker for scoring histological damage.

In conclusion, we have revealed that ET-2-like immunoreactivity is localized mainly to epithelial cells of the mucosal layer in the intestinal tract. Intracellularly, intestinal ET-2 is concentrated in the vicinity of the basement membrane. These findings suggest that ET-2 may be secreted from the basement membrane of epithelial cells. Furthermore, ET-2 may act as a chemoattractant for macrophages to the lamina propria and might modulate the function of immune cells for mucosal defense. Further study is needed to confirm this premise and support ET-2 as a potential therapeutic target for intestinal disorders such as IBD.

\section{Acknowledgements}

We thank Dr T Imamura (AIST) for allowing us use of a cryostat. K S gratefully thanks Dr K Nakamura, Dr S Oka, Dr M Iwakura, Dr H Kuriyama, Dr E Niki and Dr T Katsura (AIST), and Professor H Sawada (University of Nagoya) for their encouragement. J A is a NEDO Industrial Technology Researcher on leave from the Microscopy Laboratory, School of Bioengineering, National University of Entre Rios, Entre Rios, Argentina. J Q is a recipient of a Japan Society for the Promotion of Science (JSPS) fellowship. The authors declare that there is no conflict of interest that would prejudice the impartiality of this scientific work.

\section{Funding}

This work was supported by a special grant to K. S. from the Ministry of Economy, Trade and Industry of Japan and by a grant-in-aid for scientific research (Number 17580089) from the Japan Society for the Promotion of Science.

\section{References}

Baynash AG, Hosoda K, Giaid A, Richardson JA, Emoto N, Hammer RE \& Yanagisawa M 1994 Interaction of endothelin-3 with endothelin-B receptor is essential for development of epidermal melanocytes and enteric neurons. Cell 79 1277-1285.

Bloch KD, Hong CC, Eddy RL, Show TB \& Quertermous T 1991 cDNA cloning and chromosomal assignment of the endothelin 2 gene: vasoactive intestinal contractor peptide is rat endothelin 2 . Genomics 10 236-242.

Boivin B, Chevalier D, Villeneuve LR, Rousseau E \& Allen BG 2003 Functional endothelin receptors are present on nuclei in cardiac ventricular myocytes. Fournal of Biological Chemistry $\mathbf{2 7 8}$ 29153-29163.

Coulombe M, Battistini B, Stankova J, Pouliot P \& Bissonnette EY 2002 Endothelins regulate mediator production of rat tissue-cultured mucosal mast cells. Up-regulation of Th1 and inhibition of Th2 cytokines. Fournal of Leukocyte Biology $\mathbf{7 1}$ 829-836. 
de la Monte S, Quertermous T, Hong CC \& Bloch KD 1995 Regional and maturation-associated expression of endothelin 2 in rat gastrointestinal tract. Fournal of Histochemistry and Cytochemistry 43 203-209.

Egidy G, Juillerat-Jeanneret L, Korth P, Bosman FT \& Pinet F 2000 The endothelin system in normal human colon. American Fournal of Physiology Gastrointestinal and Liver Physiology $\mathbf{2 7 9}$ G211-G222.

Escrig C, Bishop AE, Inagaki H, Moscoso G Takahashi K, Varndell IM, Ghatei MA, Bloom SR \& Polak JM 1992 Localization of endothelin like immunoreactivity in adult and developing human gut. Gut 33 212-217.

Fang S, Ledlow A, Murray JA, Christensen J \& Conklin JL 1994 Vasoactive intestinal contractor: localization in the oppossum esophagus and effects on motor function. Gastroenterology 107 1621-1626.

Giannasca PJ, Giannasca KT, Falk P, Gordon JI \& Neutra MR 1994 Regional differences in glycoconjugates of intestinal M cells in mice: potential targets for mucosal vaccines. American fournal of Physiology Gastrointestinal and Liver Physiology 276 G1 108-G1121.

Grimshaw MJ, Naylor S \& Balkwill FR 2002a Endothelin-2 is a hypoxia-induced autocrine survival factor for breast tumor cells. Molecular Cancer Therapeutics 1 1273-1281.

Grimshaw MJ, Wilson JL \& Balkwill FR $2002 b$ Endothelin-2 is a macrophage chemoattractant: implications for macrophage distribution in tumors. European fournal of Immunology $\mathbf{3 2}$ 2393-2400.

Grimshaw MJ, Hagemann T, Ayhan A, Gillett CE, Binder C \& Balkwill FR 2004 A role for endothelin-2 and its receptors in breast tumor cell invasion. Cancer Research 64 2461-2468.

Hogaboam CM, Muller MJ, Collins SM \& Hunt RH 1996 An orally active non-selective endothelin receptor antagonist bosentan, markedly reduced injury in a rat model of colitis. European fournal of Pharmacology 309 261-269.

Inagaki H, Bishop AE, Escrig C, Wharton J, Allen-Mersh TG \& Polak JM 1991 Localization of endothelinlike immunoreactivity and endothelin binding sites in human colon. Gastroenterology 101 47-54.

Inoue A, Yanagisawa M, Kimura S, Kasuya Y, Miyauchi T, Goto K \& Masaki T 1989 The human endothelin family: three structurally and pharmacologically distinct isopeptides predicted by three separate genes. PNAS $\mathbf{8 6} 2863-2867$.

Ishida N, Tsujioka K, Tomio M, Saida K \& Mitsui Y 1989 Differential activities of two distinct endothelin family peptides on ileum and coronary artery. FEBS Letters 247 337-340.

Iwashima A, Kobayashi M, Saida K, Kagamu H, Ohashi S, Arakawa M \& Mitsui Y 1997 Contraction and intracellular calcium-ion elevation of cultured human aortic smooth muscle cells by endothelin-1, vasoactive intestinal contractor (VIC) and the derivatives. In Vitro Cellular and Developmental Biology (Animals) 33 751-756.

Kedzierski RM \& Yanagisawa M 2001 Endothelin systems: the double-edged sword in health and disease. Annual Review of Pharmacology and Toxicology 41 851-876.

Kozeki C, Imai M, Hirata Y, Yanagisawa M \& Masaki T 1989 Autoradiographic distribution in rat tissues of binding sites for endothelin: a neuropeptide? American Fournal of Physiology Regulatory, Integrative and Comparative Physiology 256 R858-R866.

Lauber K, Bohn E, Kröber SM, Xiao Y, Blumenthal SG, Lindemann RK, Marini P, Wiedig C, Zobywalski A, Baksh S et al. 2003 Apoptotic cells induce migration of phagocytes via caspase-3-mediated release of a lipid attraction signal. Cell $\mathbf{1 1 3}$ $717-730$.

Liu Y, Yamada H \& Ochi J 1998 Immunohistochemical studies on endothelin in mast cell and macrophages in the rat gastrointestinal tract. Histochemistry and Cell Biology 109 301-307.

Massai L, Carbotti P, Cambiaggi C, Mencarelli M, Migliaccio P, Muscettola M \& Grasso G 2003 Prepro-endothelin-1 mRNA and its mature peptide in human appendix. American fournal of Physiology Gastrointestinal and Liver Physiology 284 G340-G348.

Masuo Y, Ishikawa Y, Kozakai T, Uchide T, Komatsu Y \& Saida K 2003 Vasoactive intestinal contractor / endothelin-2 gene expression in the murine central nervous system. Biochemical and Biophysical Research Communications 300 661-668.

McCartney SA, Ballinger AB, Vojnovic I, Farthing MJG \& Warner TD 2002 Endothelin in human inflammatory bowel disease: comparison to rat trinitrobenzenesulphonic acid-induced colitis. Life Sciences 71 1893-1904.

Murch SH, Braegger CP, Sessa WC \& MacDonald TT 1992 High endothelin-2 immunoreactivity in Crohn's disease and ulcerative colitis. Lancet 339 381-385.

Okabe H, Chijiiwa Y, Nakamura K, Yoshinaga M, Akiho H, Harada N \& Nawata H 1995 Two endothelin receptors $\left(\mathrm{ET}_{\mathrm{A}}\right.$ and $\mathrm{ET}_{\mathrm{B}}$ ) expressed on circular smooth muscle cells of guinea pig cecum. Gastroenterology 108 51-57.

Okayasu I, Hatakeyama S, Yamada M, Ohkusa T, Inagaki Y \& Nakaya R 1990 A novel method in the induction of reliable experimental acute and chronic ulcerative colitis in mice. Gastroenterology 98 694-702.

Saida K, Mitsui Y \& Ishida N 1989 A novel peptide, vasoactive intestinal contractor, of a new (endothelin) peptide family. Molecular cloning, expression, and biological activity. Fournal of Biological Chemistry 264 14613-14616.

Saida K, Hashimoto M, Mitsui Y, Ishida N \& Uchide T 2000 The prepro vasoactive intestinal contractor (VIC)/endothelin-2 gene (EDN2): structure, evolution, production, and embryonic expression. Genomics 64 51-61.

Sundler F, Ekblad E, Grunditz T, Hakanson \& Uddman R 1988 Vasoactive intestinal peptide in the peripheral nervous system. Annals of the New York Academy of Sciences 527 143-167.

Takahashi K, Jones PM, Kanse SM, Lam H-C, Spokes RA, Ghatei MA \& Bloom SR 1990 Endothelin in the gastrointestinal tract: Presence of endothelinlike immunoreactivity, endothelin-1 messenger RNA, endothelin receptors, and pharmacological effect. Gastroenterology 99 1660-1667.

Takahashi-Iwanaga H, Iwanaga T \& Ishikawa H 1999 Porosity of the epithelial basement membrane as an indicator of macrophage-enterocyte interaction in the intestinal mucosa. Archive of Histology and Cytology 62 471-481.

Takizawa S, Uchide T, Kozakai T, Adur J, Quan J \& Saida K 2004 Immunolocalization of endothelin-B receptor in mouse intestinal tract. Fournal of Cardiovascular Pharmacology 44 S329-S331.

Uchide T, Masuda H, Mitsui Y \& Saida K 1999 Gene expression of vasoactive intestinal contractor/endothelin-2 on ovary, uterus and embryo: comprehensive gene expression profiles of the endothelin ligand-receptor system revealed by semi-quantitative reverse transcription-polymerase chain reaction analysis in adult mouse tissues and during late embryonic development. Fournal of Molecular Endocrinology 22 161-171.

Uchide T, Adur J, Fukamachi H \& Saida K 2000a Quantitative analysis of endothelin-1 and vasoactive intestinal contractor/endothelin-2 gene expression in rats by real-time reverse transcriptase polymerase chain reaction. Fournal of Cardiovascular Pharmacology 36 S5-S8.

Uchide T, Adur J \& Saida K $2000 b$ Rapid quantification of murine endothelin-1 and vasoactive intestinal contractor gene expression levels by a real-time PCR system. Fournal of Biotechnology $\mathbf{8 4}$ 187-192.

Zuidervaart W, van der Velden PA, Hurks MH, van Nieuwpoort FA, Out-Luiting CJJ, Singh AD Frants RR, Jager MJ \& Gruis NA 2003 Gene expression profiling identifies tumor markers potentially playing a role in uveal melanoma development. British Fournal of Cancer $\mathbf{8 9}$ 1914-1919.

Received 6 June 2005

Accepted 15 June 2005 